\title{
A (I)MATERIALIDADE DO LIMITE E DA FRONTEIRA
}

\author{
The materiality and immateriality of the limits and boundary
}

A (i)materialidad de los límites y fronteras

\author{
Leonardo Luiz Silveira da Silva* \\ Juarez Augusto Silveira da Silva** \\ *Doutor em Geografia - leoluizbh@hotmail.com \\ ** Historiador e especialista em docência no ensino superior- juahistory@hotmail.com \\ Recebido em 07/05/2020. Aceito para publicação em 08/07/2020 \\ Versão online publicada em 24/11/2020 (http://seer.ufrgs.br/paraonde)
}

\begin{abstract}
Resumo:
Assim como diversos conceitos geográficos, os limites e fronteiras possuem significados que perpassam pelos domínios da materialidade e da imaterialidade. Os tradicionais significados associados a um ordenamento jurídico contrastam com os significados intersubjetivos, que são, por sua vez, construídos pela experiência humana. A concepção de Augustin Berque acerca dos geogramas nos ajuda a ordenar este imbróglio teórico, permitindo-nos sugerir uma justa medida na abordagem dos limites e fronteiras. Deste modo, é o objetivo deste artigo abordar o significado dos limites e fronteiras de forma a mediar a materialidade e a imaterialidade que estão, por sua vez, dialeticamente envolvidas.
\end{abstract}

Palavras-chave: Limites; Fronteira; materialidade; imaterialidade.

\begin{abstract}
:
Like various geographical concepts, limits and boundaries have meanings that span the domains of materiality and immateriality. The traditional meanings associated with a legal order contrast with the intersubjective meanings, which, in turn, are constructed by human experience. Augustin Berque's conception of geograms helps us to organize this theoretical imbroglio, allowing us to suggest a measure in the approach of limits and boundary. Thus, the aim of this article is to address the meaning of limits and boundary in order to mediate the materiality and immateriality that are, in turn, dialectically involved.
\end{abstract}

Key words: Limits; Boundary; materiality; immateriality.

\section{Resumen:}

Al igual que varios conceptos geográficos, los límites y las fronteras tienen significados que abarcan los dominios de materialidad e inmaterialidad. Los significados tradicionales asociados con un orden legal contrastan con los significados intersubjetivos, que, a su vez, son construidos por la experiencia humana. La concepción de los geogramas de Augustin Berque nos ayuda a organizar este embrollo teórico, lo que nos permite sugerir una medida justa en el enfoque de límites y fronteras. Por lo tanto, el objetivo de este artículo es abordar el significado de límites y fronteras para mediar en la materialidad y la inmaterialidad que, a su vez, están dialécticamente involucradas.

Palabras clave: límites; Frontera; materialidad; inmaterialidad 


\section{Introdução}

Os estudos de limites e fronteiras possuem uma história longa, descritiva e, pelo menos em boa parte do seu percurso, pobre no que se refere ao debate epistemológico. Em parte, isto é explicado pelo fato destas categorias serem materializadas como uma questão das relações internacionais baseadas em princípios práticos e, em alguns casos, técnicos (NEWMAN e PAASI, 1998). Por outro lado, sabemos que no senso comum, limites e fronteiras são palavras utilizadas em sentidos que não condizem com o seu significado geográfico. Isto se deve, também, pelo fato do estudo destas duas categorias não ser exclusividade da geografia, sendo objeto de estudo de antropólogos, cientistas políticos, sociólogos, planejadores urbanos, estudiosos ambientais, dentre outros (TAGLIACOZZO, 2015). Cada uma destas disciplinas conceitua os limites e as fronteiras com ênfases variadas. Entretanto, o consenso é de que estas duas categorias são construções humanas, criadas para controlar 0 comportamento humano em um contexto espacial (HATALEY e LEUPRECHT, 2018), o que atende aos desígnios do mainstream construtivista das relações internacionais (JACKSON e SORENSEN, 2007; WENDT, 1992).

Os tradicionais entendimentos objetivos acerca dos fatos geográficos, associados à uma metodologia (neo)positivista que buscava para além do exercício do ofício a legitimação da geografia como ciência (SCHAEFER, 1953; HARVEY, HARTSHORNE, 1978; SACK, 1972 e 1974; SMITH, 1979; CAPEL,2013), encontraram correntes que desafiaram o seu monopólio. Foi justamente na virada cultural que floresceu entre os anos 1960 e 1970 (VALENTINE, 2001) que uma pletora de desafios se lançou frente ao domínio objetivista, colaborando para uma série de debates sobre os significados.

Assim, a polarização envolvendo a objetividade e a subjetividade, bem como sobre a essência material e imaterial dos fatos geográficos se lançou, aproveitando-se do movimento interdisciplinar da virada cultural que trouxe repercussões para muito além da geografia. Assistimos então a desconstrução e reconstrução de significados antes dotados de certa estabilidade, o que motivou modificações nas estratégias discursivas e maior zelo com o emprego das palavras. Foi no meio deste contexto que ocorreu o embate entre Don Mitchell e outros nomes da geografia cultural sobre os efeitos nocivos da reificação da cultura (MITCHELL, 1995 e 1996; COSGROVE, 1996; DUNCAN e DUNCAN, 1996; JACKSON, 1996) bem como o debate de Marie Price e Martin Lewis acerca da validade dos pressupostos da escola de Berkeley na pesquisa geográfica pós-Carl Sauer (PRICE e LEWIS, 1993a e 1993; COSGROVE, 1993; DUNCAN, 1993; JACKSON, 1993).

Dito isso, é plausível considerar a existência de sérias assimetrias que envolvem o uso jurisdicional dos conceitos de limites e fronteiras e o seu sentido intersubjetivo, que vai além da materialidade, penetrando no complexo ato perceptivo das pessoas, sejam suas experiências com estes conceitos fabricadas enquanto insiders ou outsiders[i] (RELPH, 1976). É objetivo deste artigo abordar o significado dos limites e fronteiras para além de sua materialidade (mas partindo e retornando a ela), tendo como inspiração a formulação de Augustin Berque (2012) acerca dos geogramas. Para tanto,

ParaOnde!?, Porto Alegre, v.14, n.1, p.13-30, 2020.http://seer.ufrgs.br/paraonde 
apresentaremos as convencionais definições de limite e fronteiras; faremos uma reflexão sobre a materialidade e a imaterialidade como forma de substanciar nosso arcabouço teórico; proporemos os significados de limites e fronteiras como geogramas e, por fim, teceremos as considerações finais.

\section{Desenvolvimento}

\subsection{Limites e Fronteiras}

A partir de uma abordagem centrada na multidisciplinaridade, consideramos que o limite é uma linha natural[ii] ou artificial que contorna o extremo do território físico do Estado. O limite jurídico do território é uma abstração que, por ser reconhecida como definidora do espaço territorial, acaba se constituindo como um instrumento de separação entre unidades políticas e soberanas (MACHADO, 2000).

A fronteira, por sua vez, é a faixa contígua à linha do limite. Temos, a partir destas definições, clareza quanto às distintas geometrias entre os limites e as fronteiras. Estas últimas possuem usualmente sua extensão artificial, definida a partir dos interesses do Estado que as abriga. Como normalmente os Estados estabelecem a extensão da faixa de fronteira, são diminutas as brechas para as interpretações subjetivas deste valoroso conceito geográfico. Em grande medida, esta é a explicação para que os estudos de fronteira gradativamente tenham passado a entender as fronteiras como instituições que resultam das políticas de fronteira (BRUNET-JAILLY, 2012), em contraste com a ideia simples de linhas desenhadas na areia ou em um mapa. Como toda instituição, as fronteiras possuem um rol de regras internas que dirigem o seu comportamento, alguns dos quais se transformam resistentes às mudanças (NEWMAN, 2003). Contudo, as regulamentações da fronteira são passíveis de experimentar mudanças.

Há duas interpretações para a origem etimológica da palavra fronteira. A primeira remete à palavra "fronteria" ou "frontaria", indicando a porção do território situado "in fronte", ou seja, nas margens. A segunda estaria ligada a palavra "front" ou "la ligne de front", dando um sentido militar-estratégico à região da fronteira e sugerindo ser esta uma área marcada por tensões, onde as soberanias territoriais se encontram (NOGUEIRA, 2007). A distinção entre regiões de fronteira e linhas fronteiriças (limites) é significativa para se estabelecer os diferentes sentidos da fronteira para os Estados modernos e os tradicionais (pré-vestfalianos, como os impérios romanos e chineses). Nos Estados modernos, a fronteira é melhor delimitada, possuindo limites que definem a espessura de sua faixa. Nos Estados tradicionais, a ideia de fronteira era expressa como uma zona, sem delimitação muito precisa (CAIRO CAROU, 2001).

A despeito do uso do senso comum, que aplica o conceito de fronteira às mais diversas realidades, confundindo-o, inclusive, com o conceito de limite (MATTOS, 1990), temos nos estudos geopolíticos e da Geografia Política definições muito claras e desprovidas de ambiguidades. A fronteira constitui-se no campo dos estudos políticos aplicados ao espaço como uma área

ParaOnde!?, Porto Alegre, v.14, n.1, p.13-30, 2020.http://seer.ufrgs.br/paraonde 
convencionada que segue as normas do direito internacional como, também, as leis e constituições dos interessados em delimitá-la (ABINZANO, 2015). Por esta razão, a extensão da Faixa de Fronteira varia de acordo com as resoluções de cada país. Geralmente sua extensão integra o texto da carta magna, como ocorre no Brasil. Se as fronteiras e os limites existem, sempre haverá alguém disposto a atravessá-los para acessar o outro lado. O gerenciamento de fronteiras possui como escopo os procedimentos necessários para facilitar ou restringir a sua travessia (NEWMAN, 2006a). No caso brasileiro, assim diz o trecho da constituição que aborda a extensão da faixa de fronteira:

A faixa de até $150 \mathrm{~km}$ de largura, ao longo das fronteiras terrestres, designada como faixa de fronteira, é considerada fundamental para a defesa do território nacional e sua ocupação e utilização serão regulamentadas por lei (BRASIL, Cap.II, Art.20, alínea XI, parágrafo II, 1988).

Poucos países podem ter faixa de fronteira com a extensão de $150 \mathrm{~km}$, sob o risco de muitos deles possuírem a totalidade ou mesmo a maior parte dos seus territórios inseridos no interior desta faixa. Com dimensões territoriais colossais e com uma das mais extensas faixas de fronteira do mundo, sendo parte importante delas em zonas despovoadas que geram apreensão quanto à segurança e integridade territorial, o Brasil tem motivos para se tornar um expoente nos estudos fronteiriços.

A faixa de fronteira boliviana possui a extensão de $50 \mathrm{~km}$. A preocupação com a segurança se destaca no próprio texto constitucional ao ser referida como "zona de segurança de fronteira". No artigo 261 da constituição boliviana em que a faixa de fronteira é definida, já se apresenta a proibição de posse estrangeira de propriedades. Esta é uma das faces da bandeira nacionalista deflagrada pelo governo Evo Morales, e que atingiu os interesses de brasileiros que vivem ou viviam na fronteira entre o Brasil e a Bolívia.

\footnotetext{
Constitui-se zona de segurança de fronteira os cinquenta quilômetros a partir da linha da fronteira. Nenhuma pessoa estrangeira, individualmente ou em sociedade, poderá adquirir propriedade neste espaço, direta ou indiretamente, nem possuir nenhum título de propriedade de água, solo ou subsolo. A propriedade ou a posse afetada em caso de descumprimento desta proibição passarão ao benefício do Estado sem nenhuma indenização. A lei poderá prever exceções a esta proibição (BOLíVIA, Art.261, linha I, 2009).
}

Deste modo, o fragmento constitucional boliviano apresentado revela como a experiência histórica, seja analisada no âmbito de cada sociedade ou de cada Estado, interfere na forma de ver a fronteira. As raízes históricogeográficas da formação e da dilapidação do território boliviano (DINIZ E CAMPOLINA, 2006) deixaram sequelas no pensamento geopolítico do país. Estas fazem com que os pratos da balança fronteiriça que antagonizam as variáveis segurança e a cooperação como funções prioritárias da fronteira pesem mais na primeira variável. Contudo, estas observações compõem uma leitura de momento, afinal, a experiência histórica se manifesta diacronicamente. Sendo assim, a mesma ainda está em curso, fazendo com

ParaOnde!?, Porto Alegre, v.14, n.1, p.13-30, 2020.http://seer.ufrgs.br/paraonde 
que as posições relativas quanto à segurança e à cooperação possam se modificar ao sabor de novas experiências. A extensão de duas faixas de fronteira adjacentes constitui a Zona de Fronteira (MACHADO et. al., 2005). Somando a extensão da faixa de fronteira brasileira com a boliviana, concluímos que a extensão da zona de fronteira Brasil-Bolívia é de $200 \mathrm{~km}$.

Os limites e as fronteiras são produzidos a partir das dinâmicas de territorialização e territorialidade. Estudos sobre a formação territorial dos países costumam ser riquíssimos e permeados de tratativas diplomáticas e eventos beligerantes. Arranjos e rearranjos das redes são instrumentos eficazes e indispensáveis para a compreensão de processos de ampliação e fragmentação territorial. As fronteiras terrestres são as de questionamento mais antigo. Em função disto encontra-se bastante consolidado no direito internacional a regulação do seu traçado e de sua funcionalidade. Há de se destacar que a aceitação de uma linha de limites pelos países confinantes, seja ela natural ou artificial, não deve dispensar a necessidade de sua demarcação física. As mais diversas fronteiras naturais possuem regras de demarcação bem claras (Mattos, 1990).

Como foi dito, as relações de um poder territorial com a sua faixa de fronteira não pode ser entendida como algo permanente que perpassa pelo tempo e pelos governos e regimes políticos. As faixas de fronteiras experimentam mudanças que estão diretamente associadas a fatores como:

- Novo dinamismo nos territórios fronteiriços adjacentes. Mudanças rápidas na faixa de fronteira do vizinho muitas vezes sugerem uma reação no que tange ao ordenamento da gestão territorial desta região estratégica do Estado;

- Mudanças governamentais que implicam em modos diferentes de se ver a fronteira. Geralmente estas mudanças implicam em um rearranjo do equilíbrio entre as funções de segurança e de plataforma de cooperação, não sendo este equilíbrio, necessariamente, um jogo de soma zero;

- Mudanças internacionais que passaram a exigir mais fluidez e porosidade nos fluxos internacionais, com o barateamento dos custos de transporte em escala global;O

- O enfraquecimento institucional do Estado, que pode ser menos capaz de fazer valer sua presença nas áreas periféricas, permitindo o surgimento de múltiplas territorialidades e o aumento das relações informais transfronteiriças;

- O status quo diplomático que envolvem os países que compartilham a zona de fronteira. Por exemplo, as diferenças observadas entre a zona de fronteira alemã e francesa é bem distinta daquelas observadas entre a Coreia do Sul e do Norte. O status diplomático é um dos principais vetores da diferença em questão.

A pluralidade de fatores que interferem no arranjo das fronteiras inspirou um modelo classificatório das condições espaço-temporais das mesmas (SILVA, 2018). Neste modelo evitou-se a utilização da palavra estágios, se referindo às distintas condições da fronteira ao longo do tempo. Esta tentativa se explica pela associação inequívoca da palavra estágio frente a uma lógica positivista-determinista que simplifica a diversidade e complexidade da fronteira

ParaOnde!?, Porto Alegre, v.14, n.1, p.13-30, 2020.http://seer.ufrgs.br/paraonde 
entendida enquanto categoria geográfica. A palavra estágio ainda denota uma evolução linear, o que não se aplica ao caso das chamadas condições espaçotemporais da fronteira. O uso da expressão "condição espaço-temporal" não é um eufemismo determinista; trata-se de um convite à compreensão do dinamismo da fronteira, de sua heterogeneidade enquanto periferia de uma entidade territorial e da possibilidade das fronteiras se apresentarem plurais tanto no tempo quanto espaço.

Foram classificadas quatro condições espaço-temporais das fronteiras e expostas as suas características:

Quadro 1 - As condições espaço-temporais da fronteira

\begin{tabular}{|c|c|}
\hline $\begin{array}{l}\text { Condição Espaço- } \\
\text { Temporal da } \\
\text { Fronteira }\end{array}$ & Características \\
\hline \multirow{3}{*}{ Fraqueza } & Dificuldades técnicas para se estabelecer os limites \\
\hline & Reconhecimento internacional não consensual \\
\hline & Fragilidade de conexão das fronteiras com os centros de comando e controle \\
\hline \multirow{6}{*}{ Força } & Avanços superam as dificuldades técnicas para o estabelecimento dos limites \\
\hline & Fundação das cidades-vigilantes \\
\hline & Reconhecimento dos limites por parte dos vizinhos \\
\hline & Adensamento das redes que conectam os centros de comando e controle à fronteira \\
\hline & Definição institucional da extensão da faixa de fronteira \\
\hline & $\begin{array}{l}\text { Aplicação de políticas direcionadas ao fortalecimento econômico orientado para o espaço } \\
\text { intranacional }\end{array}$ \\
\hline \multirow{3}{*}{ Porosidade } & $\begin{array}{l}\text { Aplicação de políticas direcionadas ao fortalecimento econômico orientado para o espaço } \\
\text { internacional }\end{array}$ \\
\hline & Fluxos transnacionais tornam-se relevantes frente aos fluxos intranacionais \\
\hline & $\begin{array}{l}\text { Questões internacionais tornam-se tão relevantes quanto às questões domésticas para a } \\
\text { comunidade fronteiriça }\end{array}$ \\
\hline \multirow[b]{2}{*}{ Colapso } & $\begin{array}{l}\text { Fluxos transnacionais da legalidade (controlados pelo estado) irrisórios frente aos fluxos da } \\
\text { ilegalidade. }\end{array}$ \\
\hline & $\begin{array}{l}\text { Sintomas geralmente associados à condição de Estado Falido se manifestam } \\
\text { notoriamente, tais como a deslegitimação do Estado, a falência dos serviços públicos, o } \\
\text { desrespeito aos direitos humanos e o registro de fluxo de refugiados. }\end{array}$ \\
\hline
\end{tabular}

ParaOnde!?, Porto Alegre, v.14, n.1, p.13-30, 2020.http://seer.ufrgs.br/paraonde 
As quatro condições espaço-temporais da fronteira não se constituem como estágios temporais. Dessa forma, não é esperado que tais condições apresentem-se como etapas necessárias de um processo evolutivo irremediável. Apesar da tentativa classificatória, consideramos a possibilidade da fronteira reunir elementos de diferentes categorias em um mesmo momento temporal. Assim, apesar de se referirem às modificações na forma dos Estados de ver e lidar com a fronteira como "a mecânica da abertura gradual da fronteira" como um indicativo da "transição da guerra para a paz" (NEWMAN, 2006b), é ilusório achar que o entendimento dos Estados sobre a função e a gestão da fronteira seja o mesmo.

É plausível assumir a consideração de que a fronteira não é uma entidade estagnada na dimensão espaço-tempo. A palavra "territorialização", no remete a um ato contínuo, a um processo que, em tese, não possui uma meta final. $\mathrm{O}$ Estado tem em suas mãos a capacidade de estabelecer políticas especiais na Faixa de Fronteira visando à intensificação da territorialização e à multiplicação e sobreposição das mais variadas redes. É importante destacar, contudo, que o esforço do governo no sentido de se colocar como o principal partícipe da territorialização precisa ser harmoniosamente direcionado. Intervenções espaciais descoordenadas do Estado podem auxiliar a proliferar redes não estatais que, no âmbito das múltiplas territorialidades, podem possibilitar e mesmo estimular a existência de poderes paralelos. Ademais, intervenções espaciais podem incentivar redes estrangeiras a se lançar sobre o território periférico nacional, colocando em risco o território de facto. A complexidade da faixa de fronteira exige acompanhamento sistemático por parte do planejamento territorial. Em um simples exemplo, sabemos que mudanças bruscas cambiais podem estimular um rearranjo das redes transnacionais seja em sua espessura (volume dos fluxos) ou sentido (direção dos fluxos que unem os fixos). As assimetrias econômicas podem dar forma a arranjos regionais de fluxos bem específicos e que já são até mesmo nominados pela literatura acadêmica: chamadas de economias de arbitragem, tais assimetrias são marcadas por lucros e perdas obtidas devido a diferenciais de câmbio e juros, diferenças nas legislações ambientais ou trabalhistas, de diferenças nos regimes políticos ou normas institucionais. Estas diferenças exploram, legal ou ilegalmente, a existência dos limites internacionais (MACHADO, 2005).

Ademais, reconhecemos o fato de que, embora as linhas internacionais dividam nações, comunidades de fronteira podem permanecer unidas pela cultura, etnicidade, língua, religião ou mesmo pela natureza das instituições políticas. A essência das organizações políticas locais e da cultura influencia também a natureza das fronteiras, sendo que a sua dinâmica dependerá também do ativismo das comunidades fronteiriças (BRUNET-JAILLY, 2005). Para além da definição jurídica, há um entendimento dos limites e fronteiras pautado pela intersubjetividade e pelas noções práticas cotidianas. Uma miríade de significados transborda para além do tratamento acadêmico convencional destes termos. Ignorar este transbordamento significa está em desacordo com os potenciais práticos dos conceitos de limite e fronteira. Esta discussão nos conduz ao debate sobre a materialidade e a imaterialidade dos fatos geográficos.

ParaOnde!?, Porto Alegre, v.14, n.1, p.13-30, 2020.http://seer.ufrgs.br/paraonde 


\title{
2.2. Materialidade e Imaterialidade dos fatos geográficos
}

De que forma a objetividade e a subjetividade impactam na leitura do espaço geográfico? Para discutirmos o ato de percepção e expressão do espaço, faz-se necessário compreender que a percepção, a cognição e a avaliação espacial são processos extremamente inter-relacionados (NASSAUER, 1995). Ademais, é importante destacar que a percepção não é o mesmo que sensação. A percepção, principalmente a visual, não se trata da recepção puramente passiva dos dados sensoriais, mas sua interpretação e organização em uma estrutura que lhe dá forma e sentido (COLLOT, 2015). Esta noção nos deixa claro que a percepção da paisagem, por exemplo, é mais do que a simples resposta ao estímulo visual[iii] (AOKI, 1999). Os demais sentidos e a memória trabalham em um esquema complexo que é responsável pela elaboração dos significados. As sensações, assim, são componentes necessários da percepção, mas não podem assumir toda a sua dimensão. Inspirados nesta reflexão apriorística, nos perguntamos: existe uma parcela de objetividade na percepção do espaço?

É necessário refletir o espaço a partir do olhar sobre a sua categoria que melhor representa as relações entre o homem e o meio ao qual está inserido: a paisagem. Dito isso, é importante apontar que os sentidos das palavras objetividade e subjetividade aplicados à percepção da paisagem apresentam duas faces. A subjetividade pode expressar a variação de entendimento e de percepção que uma pessoa tem acerca de um fenômeno ou objeto; por outro lado, pode significar o entendimento diverso que as pessoas têm acerca dos elementos constituintes da paisagem[iv] (CLAMP, 1981). A objetividade, por sua vez, pode se manifestar na reificação dos elementos da paisagem, que passam a ser passíveis de uma descrição que pretende esgotar as dimensões do ente. Alternativamente, em uma visão coletiva, a objetividade pode ser entendida como uma proposição consensual entre indivíduos. É em função destas diferenças de entendimento sobre a objetividade e a subjetividade que não podemos simplesmente atrelar a materialidade ao campo objetivo e a imaterialidade ao subjetivo.

Para Pires (2017) a paisagem é construída pela objetividade e subjetividade, que se encontram no momento percebido e interpretativo. Além disso, a autora assevera:

\begin{abstract}
a objetividade é evidenciada a partir de um conjunto de significados culturais e simbólicos apreendidos coletivamente. A subjetividade está representada pela particularidade do olhar em relação à natureza, observando critérios simbólicos e cognitivos individuais, pois é a forma como o sujeito relaciona-se com o mundo e com outras intersubjetividades (PIRES, 2017, p.173).
\end{abstract}

A objetividade participa parcialmente da compreensão da paisagem, fato que é reforçado pelas abordagens de Gold (1980) e também Lando (1996). Concordando com Gold, Lando reforça a existência de três grandes componentes da leitura paisagística, que parecem transitar entre os extremos objetivo e subjetivo:

ParaOnde!?, Porto Alegre, v.14, n.1, p.13-30, 2020.http://seer.ufrgs.br/paraonde 
- "Os aspectos físicos tangíveis de uma área"

. "As atividades humanas mensuráveis";

- "Significados e símbolos impostos nos lugares pela consciência humana". (LANDO, 1996, p.8).

Nesse sentido, parece concordar Kenneth R. Olwig quando salienta que "o entendimento da paisagem reconhece a importância histórica e contemporânea da comunidade, cultura, lei e costumes no molde da existência geográfica do homem - tanto no campo das ideias quanto no das práticas" (OLWIG, 1996, p.645). A percepção da paisagem é, também, um ato solitário, pois envolve o acesso a "sistemas de memória bem gerenciados para o acesso às experiências do passado" (AOKI, 1999, p.85). A coletânea destas experiências do passado são obras únicas que estão guardadas nas mente de cada indivíduo. São estes argumentos que ajudam a consolidar a parcela subjetiva da essência paisagística.

A objetividade, contudo, apresenta-se frágil. Mesmos os aspectos físicos ditos tangíveis podem ser percebidos e expressos com ênfases distintas. A capacidade de identificar elementos paisagísticos pode ser uma habilidade adquirida coletivamente e manifesta em diferentes graus. Da mesma forma, a cognoscibilidade da paisagem se manifesta de uma forma não objetiva, sendo, portanto, uma gradação, que nos leva à lembrança dos trabalhos de John K. Wright:

\begin{abstract}
De fato, se olharmos de suficientemente perto - toda a Terra parece uma imensa colcha de retalhos de mini terrae incognitae. Mesmo que uma área seja minuciosamente mapeada e estudada por um exército de micro geógrafos, muito sobre sua geografia sempre permaneceria desconhecida e, deste modo, se hoje não há terra incógnita em sentido absoluto, não há também terra absolutamente cógnita (WRIGHT, 2014, p.7).
\end{abstract}

Wright discursou sobre a terra incógnita em 1946. Negou, em seu contexto, a possibilidade de existir a terra absolutamente cógnita. Ainda que consideremos os prodígios do sensoriamento remoto e das novas técnicas/tecnologias cartográficas, ainda faz sentido pensar em terras incógnitas. As imagens, disponíveis sobre parte extensa da superfície terrestre, não cobrem toda a dimensão das sensações associadas ao vivenciar. Visualizar imagens significa dimensionar expectativas, mas, não significa vivenciar ou conhecer, verbos que demandam uma pluralidade de sensações que compõem a experiência. Em contrapartida, as imagens disponíveis sobre paisagens que não vivenciamos acabam moldando nossas expectativas e interferindo na nossa forma de perceber o espaço. As paisagens exploradas por meio de muitas imagens ou relatos - de muitas fontes diversas - como por meio da indústria cinematográfica, pintura, guias turísticos e romances, não podem nos conceder a pretensão de compreender o que é "o real". O máximo que podemos nos submeter é a um processo de intermediações de narrativas, à medida que as identidades são espacialmente fendidas e temporalmente adiadas (BHABHA, 2013). "Não importa a quantidade de imagens as quais estamos expostos ou o quão claras estas imagens se apresentem em nosso

ParaOnde!?, Porto Alegre, v.14, n.1, p.13-30, 2020.http://seer.ufrgs.br/paraonde 
subconsciente, nossa visão é sempre parcial, fraturada" (COSTA, 2008, p.161). É importante mencionar esta temática, pois, na contemporaneidade, "o conhecimento da maioria das pessoas sobre a maioria dos lugares se adquire através (sic) da mídia de vários tipos, de maneira que, para a maioria das pessoas, a representação vem antes da realidade" (COSTA, 2008, p.164).

Diferentes indivíduos podem ter distintos entendimentos sobre os significados dos elementos materiais. Portanto, há a possibilidade de materializações apresentarem-se intersubjetivamente, assim como imaterialidades podem encontrar espantoso consenso (ainda que não seja absoluto) entre indivíduos.

Preocupado quanto à questão dos significados dos objetos, Berque (2012) cria uma oposição entre topos e chôra, conceitos que opõem, respectivamente, a dimensão meramente descritiva dos objetos e a descrição holística, que vai muito além de sua manifestação material. Para exemplificar a oposição destes conceitos, Berque promove a reflexão acerca de um lápis. Para além da sua descrição material, chôra abrange o conjunto das relações que envolvem um objeto, algumas das quais percebidas somente no nível intersubjetivo. Afinal, para alguém o lápis é um objeto que tem como função escrever; para outra pessoa o lápis pode significar um intocável e memorável souvenir. Desconsiderar a dimensão da chora é o mesmo que pensar em um peixe sem refletir sobre a água. Para Berque, limitar-se ao topos em nome do realismo ou do princípio de identidade seria irrealista, pois seria inferir que 0 lápis, por exemplo, a cada instante de sua existência, é criado ex nihilo (BERQUE, 2012).

Quadro 2 - Os significados do lápis entre topos e chôra

\begin{tabular}{|l|l|}
\hline \multicolumn{1}{|c|}{ Topos } & \multicolumn{1}{c|}{ Chôra } \\
\hline $\begin{array}{l}\text { Posicionamento do lápis de acordo com as } \\
\text { coordenadas geográficas; mensuração de } \\
\text { sua forma, massa e seus constituintes. Por } \\
\text { meio deste procedimento saberemos } \\
\text { fisicamente o que é um lápis. }\end{array}$ & $\begin{array}{l}\text { A função do lápis; dimensionamento simbólico } \\
\text { sobre a escrita da palavra e o que ela } \\
\text { reprenta; os processos produtivos vinculados } \\
\text { ao lápis, como a exploração florestal, o minério } \\
\text { para o grafite, as fábricas de papel (pois o lápis } \\
\text { não escreve no vazio) e os transportes para a } \\
\text { condução do lápis ao mercado. }\end{array}$ \\
\hline
\end{tabular}

Compreendendo dialeticamente a dicotomia entre topus e chôra, Berque afirma que "a realidade vai além do material, ao mesmo tempo retornando a ele também" (BERQUE, 2012, p.7). É curioso pensarmos também que as ideias humanas moldam a paisagem, ao mesmo tempo em que a experiência humana molda as ideias (WALTON, 1995). Para contemplar esta dimensão holística dos objetos materiais composta por topus e chôra, Augustin Berque sugeriu a palavra geograma ao anunciar que "imaginar a Terra sem o céu, ou o inverso, não passa de uma abstração" (BERQUE, 2012, p.8). Como dito, enquanto

ParaOnde!?, Porto Alegre, v.14, n.1, p.13-30, 2020.http://seer.ufrgs.br/paraonde 
geogramas que superam a dimensão da descrição física, os objetos não podem ser meramente descritos. O trecho a seguir explora o simbolismo que está por detrás dos corpos físicos:

\begin{abstract}
A espécie humana se tornou o que é devido a um processo imensamente longo durante o qual o fisiológico, o técnico e o simbólico não cessaram de interagir. Pelo que nos diz respeito, esta interação se traduziu por uma "exteriorização" progressiva das funções do corpo humano, que começou quando os nossos ancestrais, por assim dizer, extraíram seus incisivos de suas bocas para colocá-los na mão, na forma de pedras lascadas. Momento bem considerável e da maior eficácia! Este vantajoso processo nunca parou de se ampliar, constituindo, assim, pouco a pouco, nosso "corpo social" que é exterior ao nosso "corpo animal", que só faz estender as funções naturais que fazem parte, com todas as coisas que as compõem, de nossa corporeidade global (BERQUE, 2012, p.9).
\end{abstract}

A reflexão de Berque se associa diretamente no processo descritivo da paisagem e do lugar. Os objetos que compõem estas duas categorias geográficas vão além do seu corpo físico, constituindo-se como geogramas. A reflexão assemelha-se ao argumento de Cosgrove (1983) acerca da atividade humana. Para o autor, toda atividade humana é, ao mesmo tempo, material e simbólica, produção e comunicação.

\title{
2.3. Limites e fronteiras como geogramas
}

Pensando a respeito das significações que atribuímos aos elementos da paisagem, Jay Appleton (2000) defendeu a ideia de que os gostos e as preferências que desenvolvemos são influenciados pelo impacto da cultura[v], da sociedade e das experiências individuais. Estas variáveis de influência na composição estética de nossas preferências atuariam, na visão do autor, sobre os padrões inatos de comportamentos, alguns dos quais vinculados, por exemplo, ao instinto de sobrevivência. Apesar de considerarmos alguma validade nestes argumentos, há de reconhecer polêmica nos mesmos. É difícil conceber no complexo e variado comportamento do homem certas condições inatas atuando de forma absolutamente padronizada sobre os homens. Por outro lado, é plausível considerar que as nossas preferências estéticas interferem dramaticamente na percepção e na descrição da paisagem. Por isso concordamos com David Lowenthal (1978) quanto ao seu argumento de que o contexto da interação entre homem e meio depende:

- do humor e da circunstância;

- do tempo, da iluminação[vi] e da hora do dia;

- se a observação está sendo feita a pé ou em um veículo;

- se o observador está parado ou em movimento;

- se o objeto de contemplação foi deliberadamente escolhido ou se a interação é acidental e, portanto, inesperada (LOWENTHAL, 1978, p.375).

ParaOnde!?, Porto Alegre, v.14, n.1, p.13-30, 2020.http://seer.ufrgs.br/paraonde 
Refletindo ainda sobre o valor atribuído a paisagem, Appleton (1994) salienta que o prazer em relação à contemplação e à experiência frente a uma determinada porção do espaço se dá na interação do observador com a paisagem, independente da quantidade de objetos que nela estão inseridos e que podem carregar dimensões simbólicas. Nesse sentido, um deserto - pobre em objetos - pode se constituir aos olhos de um observador um local aprazível. A intersubjetividade na leitura da paisagem edifica constrangimentos de uma abordagem absolutamente material e objetiva da paisagem. Mostrando desalento frente à ausência de um método que costure as nuances deste vespeiro teórico, Appleton (1975) considera que para a avaliação da paisagem existe um vácuo teórico, pois não há método que seja livre de constrangimentos.

A solução para quebrar o monopólio da materialidade na análise geográfica não parece ser a aposta na intersubjetividade e na imaterialidade radicais. Por esta razão, o conceito de geogramas trazido por Augustin Berque (2012) apresenta-se formidável, por propor justamente a intermediação entre a objetividade e a subjetividade, entre o sentido estritamente material e imaterial dos fatos geográficos. Por este motivo, nos apropriaremos da reflexão de Augustin Berque para estabelecermos uma proposta de enquadramento dos conceitos de limite e fronteira enquanto geogramas.

Quadro 3 - Os significados do limite entre topos e chôra

\begin{tabular}{|l|l|}
\hline \multicolumn{1}{|c|}{ Topos (descrição material) } & \multicolumn{1}{c|}{ Chôra (descrição imaterial) } \\
\hline & $\begin{array}{l}\text { Marco das diferenças de legislação; } \\
\text { Marco do esgotamento da cidadania; } \\
\text { O que separa "nós" e "eles". } \\
\text { O que une os diferentes; } \\
\text { O que demarca o que precisamos defender; } \\
\text { Linha natural ou artificial que contorna o o o do território físico de um território. } \\
\text { Tensão e conflito; } \\
\text { Marco do estranhamento e da diferença; } \\
\text { Medo; Asco; Nojo; Diversão; } \\
\text { História; resultado do processo de luta e/ou } \\
\text { negociações diplomáticas. }\end{array}$ \\
\hline
\end{tabular}

ParaOnde!?, Porto Alegre, v.14, n.1, p.13-30, 2020.http://seer.ufrgs.br/paraonde 
Quadro 4 - Os significados da fronteira entre topos e chora

\begin{tabular}{|c|c|}
\hline Topos (descrição material) & Chôra (descrição imaterial) \\
\hline $\begin{array}{l}\text { Faixa contígua à linha do limite, de extensão } \\
\text { variável de acordo com a legislação de cada } \\
\text { Estado. }\end{array}$ & $\begin{array}{l}\text { Debates políticos que ajudaram a construir o } \\
\text { texto da constituição que estabelece a extensão } \\
\text { da faixa de fronteira. } \\
\text { Limite; } \\
\text { Espaço de oportunidades; } \\
\text { Terra sem lei; } \\
\text { Área de tensões e Conflitos; } \\
\text { Área de cooperação; } \\
\text { Espaço do crime; } \\
\text { Espaço de sacrifício pessoal em nome da pátria } \\
\text { Lar; aconchego. } \\
\text { Modo de vida peculiar; } \\
\text { Espaço de estranhamentos; } \\
\text { Espaço de fluxos; }\end{array}$ \\
\hline
\end{tabular}

É fundamental que se perceba que a descrição imaterial (chôra) não se esgota. É panglossiana a tentativa de delimitar a chôra, pois a miríade de significações faz com que qualquer levantamento, por mais hercúleo que seja, represente infinitesimalmente a totalidade intangível. Por isso optamos por conceber aleatoriamente a dimensão da chora, com o intuito de diferenciar as suas proposições da rigidez material do topos. Não existe manifestação certa ou errada da chora. De tal maneira que será possível um pesquisador, que busque coletar impressões intersubjetivas sobre os limites e fronteiras, colher relatos antagônicos que se posicionam lado a lado, num caos dantesco.

\section{Considerações Finais}

Os limites e fronteiras, assim como diversas outras categorias geográficas, deslizam elusivamente entre a materialidade e a imaterialidade. Recomenda-se fortemente que os pesquisadores dos limites e fronteiras considerem a transcendência entre topos e chora, que nos levam à concepção dos geogramas cunhada por Augustin Berque (2012). Desconsiderar a essência transcendente dos fatos geográficos - entendidos como fenômenos ou objetos - é posicionar-se no âmbito do radicalismo materialista ou imaterialista.

Já é muito problematizado desde a virada cultural que o monopólio da materialidade nos conduz à negligência quanto às percepções intersubjetivas acerca dos fatos geográficos. A abordagem estritamente material é nociva por esquecer-se das múltiplas impressões abrigadas pelas consciências humanas,

ParaOnde!?, Porto Alegre, v.14, n.1, p.13-30, 2020.http://seer.ufrgs.br/paraonde 
fazendo-nos pretender, pelo menos na dimensão aparente, executar o exercício da imposição do olhar egocêntrico que estará sob o escrutínio de uma diversidade inquieta.

Por outro lado, a radicalização da imaterialidade, pode nos conduzir a outros problemas teóricos. Ao conceber a imaterialidade extrema, todas as consequências das relações de poder, que possuem efeitos muito reais sobre a sociedade e sobre a paisagem, podem passar a ser entendidas como elementos passíveis da observação intersubjetiva, sendo até mesmo a miséria e a escravidão, em exemplos extremados, passíveis de relativização. Talvez por isso Peter Jackson alerta que "precisamos transcender o dualismo existente entre o "econômico" e o "cultural" se quisermos fazer sérios progressos na compreensão das culturas comerciais e sua associação com as formas materiais" (JACKSON, 1997, p.187).

É por isso que acreditamos que a abordagem de Augustin Berque se apresenta, aprioristicamente, como uma justa medida da intermediação entre materialidade e imaterialidade. Crer na força das leituras intersubjetivas dos fatos geográficos não é o mesmo que negar a dimensão material e seus efeitos. A abordagem dos limites e fronteiras baseada na concepção dos geogramas apresenta-se promissora por levar em conta os efeitos materiais do ordenamento jurídico e, ao mesmo tempo, as múltiplas concepções intersubjetivas guardadas nos recônditos dos corações e mentes. Nesse sentido, a dimensão imaterial do chôra não é um mero compêndio de curiosidades imaginativas. Afinal, as elaborações imaginativas colaboram, em um movimento dialético, para a construção da materialidade. Este processo não define deterministicamente a participação da imaterialidade na construção da materialidade, mas como mais um tijolo no muro.

\section{Referências}

ABINZANO, Roberto Carlos. Las Regiones de frontera: espacios complejos de la resistência global. In: OLIVEIRA, T.C.M de (org.) Territórios sem limites: estudos sobre fronteiras. Campo Grande: UFMS, p. 113-130, 2005.

AOKI, Yoji. Review article: trends in the study of the psychological evaluation of landscape. Landscape Research, v.24, n.1, p.85-94, 1999.

APPLETON, Jay. Landscape evaluation: the theoretical vacuum. Transactions of the Institute of British Geographers, n.66, nov., p.120-123, 1975.

APPLETON, Jay. Running before we can walk: are we ready to map "beauty"? Landscape Research, v.19, n.3, p.112-119, 1994.

APPLETON, Jay. What landscapes means to me. Landscapes, v.1, n.2, p.9497, 2000.

BERQUE, Augustin. Geogramas, por uma ontologia dos fatos geográficos. Geograficidade, v.2, n.1, verão, p.4-12, 2012.

BHABHA, Homy. O local da cultura. Belo Horizonte: Editora UFMG, 2013, $431 \mathrm{p}$.

ParaOnde!?, Porto Alegre, v.14, n.1, p.13-30, 2020.http://seer.ufrgs.br/paraonde 
BOLÍVIA. Constituição do Estado plurinacional da Bolívia. Art.261, linha I, 2009. BRASIL. Constituição Federal. Cap.II, Art.20, alínea XI, parágrafo II, 1988.

BRUNET-JAILLY, Emmanuel. Theorizing borders: An interdisciplinary perspective. Geopolitics, vol.10, 633-649, 2005.

BRUNET-JAILLY, Emmanuel. Power, Politics and Governance of Borderlands. (in) GILLES, Peter et.al. Theorizing borders through analyses of power relationships. Pie Peter Lang, 2012, 374p.

BUNKSE, Edmunds Valdemars. Feeling is believing, or landscape as way of being in the world. Geografiska Annaler, v.89, i.3, p.219-231, 2007.

CAIRO CAROU, Heriberto. Territorialidad e fronteras del estado-nación: las condiciones de la politica en un mundo fragmentado. Madrid: Politica e Sociedad, no-36, p.29-38, 2001.

CAPEL, Horácio. Neopositivismo e Geografia Quantitativa. (in): CAPEL, Horacio. Ruptura e continuidade no pensamento geográfico. Maringá: EDUEM, 2013, 190p.

CLAMP, Peter. The landscape evaluation controversy. Landscape Research, v.6, n.2, p.13-15, 1981.

COLLOT, Michel. Poesia, paisagem e sensação. Revista de Letras, v.1, n.34, p.17-26, 2015.

COSGROVE, Denis E. Towards a radical cultural geography: problems of theory. Antipode, Vol. 5, Issue I, p.1-11, 1983.

COSGROVE, Denis. On "the reinvention of Cultural geography" by Price and Lewis. Annals of the Association of American Geographers, v.83, n.3, p.515517, 1993.

COSGROVE, Denis. Ideas and culture: a response to Mitchell. Transactions of the Institute of British Geographers, V.21, p.574-575, 1996.

COSTA, Maria Helena Braga e Vaz da. Paisagem e simbolismo: representando e/ou vivendo o "real"? Espaço e cultura, UERJ, Edição comemorativa, p.157166, 2008.

DINIZ, Alexandre Magno Alves; CAMPOLINA, Maíra. Raízes históricogeográficas da formação e da dilapidação do território boliviano. Rio Claro: Geografia, V.31, nำ, p.505-526, set-dez, 2006.

DUNCAN, James. Commentary. Annals of the Association of American Geographers, v.83, n.3, p.517-519, 1993.

DUNCAN, James; DUNCAN, Nancy. Reconceptualizing the Idea of Culture in Geography: A Reply to Don Mitchell. Transactions of the Institute of British Geographers, New Series, v.21, n.3, p.576-579, 1996.

GOLD, John R. An introduction to Behavioural Geography. New York: Oxford University Press, 1980.

HARTSHORNE, Richard. Propósitos e natureza da geografia. São Paulo: Edusp, 1978, $203 \mathrm{p}$.

ParaOnde!?, Porto Alegre, v.14, n.1, p.13-30, 2020.http://seer.ufrgs.br/paraonde 
HARVEY, David. Explanation in Geography. Bristol: Edward Arnold, 1986.

HATALEY, Todd; LEUPRECHT, Christian. Determinants of cross-border cooperation. Jornal of Bordelands studies, v.33, nำ, p.317-328, 2018.

JACKSON, Peter. Berkeley and Beyond: Broadening the Horizons of Cultural Geography. Annals of the Association of American Geographers, V.83, n.3, p.519-520, 1993.

JACKSON, Peter. The idea of culture: a response to Don Mitchell. Transactions of the Institute of British Geographers, v.21, p.572-573, 1996.

JACKSON, Peter. Geography and the cultural turn. Scottish Geographical Magazine. V.113, n.3, p.186-188, 1997.

JACKSON, Robert; SORENSEN, Georg. Introdução às relações internacionais. Rio de Janeiro: Jorge Zahar, 2007.

LANDO, Fabio. Fact and Fiction: Geography and Literature. Geojournal, v.38, n.1, p.3-18, 1996.

LOWENTHAL, David. Finding valued landscapes. Progress in Human Geography, March, 1978.

MACHADO, Lia Osório. Limites e Fronteiras: da alta diplomacia aos circuitos da ilegalidade. Rio de Janeiro: Revista Território, ano V, no 8, p.7-23, jan-jul, 2000.

MACHADO, Lia Osório. et.al. O desenvolvimento da faixa de fronteira: uma proposta conceitual-metodológica. In: OLIVEIRA, T.C.M. de (Org.). Território sem limites: estudo sobre as fronteiras. Campo Grande: UFMS, 87-112, 2005a.

MACHADO, Lia Osório. Estado, Territorialidade, redes, cidades-gêmeas na zona de fronteira sul-americana (in): Silveira, M. L. (org.). Continente em chamas. Globalização e território na América Latina. Rio de Janeiro: Civilização Brasileira, p.246-284, 2005b.

MATTOS, Carlos de Meira. Geopolítica e Teoria de Fronteiras. Rio de Janeiro: Biblioteca do Exército, 1990.

MITCHELL, Don. There's No Such Thing as Culture: Towards a Reconceptualization of the Idea of Culture in Geography. Transactions of the Institute of British Geographers, New Series, v.20, n.1, p.102-116, 1995.

MITCHELL, Don. Explanation in Cultural Geography: A Reply to Cosgrove, Jackson and the Duncans. Transactions of the Institute of British Geographers, v.21, n.3, p.580-582, 1996.

MORAES, Antônio Carlos Robert. Território e História no Brasil. São Paulo, Annablume, 2005, 154p.

NASSAUER, Joan Iverson. Culture and changing landscape structure. Landscape Ecology, v.10, n.4, p.229-237, 1995.

NEWMAN, David; PAASI, Anssi. Fences and neighbours in the postmodern world: boundaries narratives in Political Geography. Progress in Human Geography, Vol.22, nำ, p.186-207, 1998.

NEWMAN, David. On Borders and Power: a Theoretical Framework. Journal of

ParaOnde!?, Porto Alegre, v.14, n.1, p.13-30, 2020.http://seer.ufrgs.br/paraonde 
borderlands studies, Vol.18, №1, spring, 2003.

NEWMAN, David. The lines that continue to separe-te us: borders in our "borderless" world. Progress in Human Geography. Vol.30, n², p.143-161, 2006a.

NEWMAN, David. Borders and bordering: towards an interdisciplinary dialogue. European Journal of Social Theory. Vol.9, nำ, p.171-186, 2006b.

NOGUEIRA, Ricardo José Batista. Fronteira: espaço de referência identitária? Goiânia: Ateliê Geográfico, v.1, nํ2, dez., p.27-41, 2007.

OLWIG, Kenneth R. Recovering the substantive nature of landscape. Annals of the Association of American Geographers, v.86, n.4, p.630-653, 1996.

OLWIG, Kenneth R. All that is landscape is melted into air: the "aerography" of ethereal space. Environment and Planning D: Society and Space, v.29, p.519532, 2011.

RELPH, Edward. Place and Placelesness. London: Pion Limited, 1976, 156p.

PIRES, Cláudia Luísa Zeferino. Entre o lugar e o além-lugar: o jogo de espelhos, paisagens, geografias. Uberlândia: Caminhos de Geografia, v.18, n으, 2017.

PORTEOUS, J. Douglas. Smellscape. Manchester: Progress in Human Geography, Number 9, p.356-378, 1985.

PRICE, Marie; LEWIS, Martin. The Reinvention of Cultural Geography. Annals of the Association of American Geographers. V.83, n.1, p.1-17, 1993a.

PRICE, Marie; LEWIS, Martin. Reply: On Reading Cultural Geography. Annals of the Association of American Geographers. V.83, n.3, p.520-522, 1993b.

SACK, Robert David. Geography, Geometry and Explanation. Annals of the Association of American Geographers, v.62, n.1, p.61-78, March, 1972.

SACK, Robert David. Chorology and Spatial Analysis. Annals of the Association of American Geographers, v.64, n.3, p.439-452, September, 1974.

SCHAEFER, Fred K. Excepcionalism in Geography: A methodological examination. Annals of the association of American geographers. Vol.43, number 3, p.226-249, 1953.

SILVA, Leonardo Luiz Silveira da. As condições espaço-temporais das fronteiras dos Estados. Florianópolis: Revista Geosul, v.33, nํ38, p.313-334, 2018.

SMITH, Neil. Geography, Science and post-positivist modes of explanation. Progress in Human Geography, v.3, i.3, p.356-383, 1979.

TAGLIACOZZO, Eric. Jagged landscapes: Conceptualizing borders and boundaries in the history of human societies. Journal of Borderland Studies, v.31, no1, p.1-21, 2015.

TUAN, Yi-Fu. Romantic Geography: in search of the sublime landscape. Madison: Wisconsin University Press, 2013, 205p.

ParaOnde!?, Porto Alegre, v.14, n.1, p.13-30, 2020.http://seer.ufrgs.br/paraonde 
VALENTINE, Gill. Whatever happened to the social? Reflections on the "cultural turn" in British Human Geography. Norwegian Journal of Geography, v.55, p.166-172, 2001.

WALTON, Judy R. How Real(ist) can you get? Professional Geographer, v.47, i.1, p.61-65, 1995.

WENDT, Alexander. Anarchy is what states make of it. International Organization, v.46, p.394-419, 1992.

WRIGHT, John K. Terrae Incognitae: O lugar da imaginação na Geografia. Geograficidade, v.4, n.2, inverno, p.4-18, 2014. 